\title{
A systematic bioinformatics approach for large-scale identification and characterization of host-pathogen shared sequences
}

Stephen Among James ${ }^{1,2}$, Hui San Ong ${ }^{1}$, Ranjeev Hari ${ }^{1}$ and Asif M. Khan ${ }^{1,3^{*}}$ (I)

From 19th International Conference on Bioinformatics 2020 (InCoB2020)

Virtual. 25-29 November 2020

\begin{abstract}
Background: Biology has entered the era of big data with the advent of high-throughput omics technologies. Biological databases provide public access to petabytes of data and information facilitating knowledge discovery. Over the years, sequence data of pathogens has seen a large increase in the number of records, given the relatively small genome size and their important role as infectious and symbiotic agents. Humans are host to numerous pathogenic diseases, such as that by viruses, many of which are responsible for high mortality and morbidity. The interaction between pathogens and humans over the evolutionary history has resulted in sharing of sequences, with important biological and evolutionary implications.

Results: This study describes a large-scale, systematic bioinformatics approach for identification and characterization of shared sequences between the host and pathogen. An application of the approach is demonstrated through identification and characterization of the Flaviviridae-human share-ome. A total of 2430 nonamers represented the Flaviviridae-human share-ome with $100 \%$ identity. Although the share-ome represented a small fraction of the repertoire of Flaviviridae $(\sim 0.12 \%)$ and human $(\sim 0.013 \%)$ non-redundant nonamers, the 2430 shared nonamers mapped to 16,946 Flaviviridae and 7506 human non-redundant protein sequences. The shared nonamer sequences mapped to 125 species of Flaviviridae, including several with unclassified genus. The majority ( 68\%) of the shared sequences mapped to Hepacivirus C species; West Nile, dengue and Zika viruses of the Flavivirus genus accounted for $\sim 11 \%, \sim 7 \%$, and $\sim 3 \%$, respectively, of the Flaviviridae protein sequences $(16,946)$ mapped by the share-ome. Further characterization of the share-ome provided important structural-functional insights to Flaviviridae-human interactions.

(Continued on next page)
\end{abstract}

\footnotetext{
* Correspondence: asif@perdanauniversity.edu.my; makhan@bezmialem.edu.tr

${ }^{1}$ Centre for Bioinformatics, School of Data Sciences, Perdana University, Damansara Heights, Kuala Lumpur 50490, Malaysia

${ }^{3}$ Beykoz Institute of Life Sciences and Biotechnology, Bezmialem Vakif University, Beykoz, Istanbul 34820, Turkey

Full list of author information is available at the end of the article
}

(C) The Author(s). 2021 Open Access This article is licensed under a Creative Commons Attribution 4.0 International License, which permits use, sharing, adaptation, distribution and reproduction in any medium or format, as long as you give appropriate credit to the original author(s) and the source, provide a link to the Creative Commons licence, and indicate if changes were made. The images or other third party material in this article are included in the article's Creative Commons licence, unless indicated otherwise in a credit line to the material. If material is not included in the article's Creative Commons licence and your intended use is not permitted by statutory regulation or exceeds the permitted use, you will need to obtain permission directly from the copyright holder. To view a copy of this licence, visit http://creativecommons.org/licenses/by/4.0/ The Creative Commons Public Domain Dedication waiver (http://creativecommons.org/publicdomain/zero/1.0/) applies to the data made available in this article, unless otherwise stated in a credit line to the data. 
(Continued from previous page)

Conclusion: Mapping of the host-pathogen share-ome has important implications for the design of vaccines and drugs, diagnostics, disease surveillance and the discovery of unknown, potential host-pathogen interactions. The generic workflow presented herein is potentially applicable to a variety of pathogens, such as of viral, bacterial or parasitic origin.

Keywords: Shared sequences, Share-ome, Host-pathogen, Bioinformatics, Large-scale, Methodology, Flaviviridae, Flavivirus, Hepacivirus, Pegivirus, Pestivirus, Dengue virus, West Nile virus, Hepatitis C virus, Cross-reactivity, Crossreactome, Peptide sharing, Peptide overlap, and Molecular mimicry.

\section{Background}

There has been an exponential growth of pathogen sequence data, given their relatively small genome size and important role as infectious and symbiotic agents [1-5]. This has largely been driven by high-throughput omics technologies, resulting in petabytes of data proliferating publicly available databases, providing access for knowledge discovery and study of the complex molecular descriptors of host-pathogen interactions [6, 7]. This enables detection of patterns for disease tracking and surveillance, control of pathogens, and clinical prognosis of infectious diseases, which are useful in monitoring and forecasting emerging pathogens $[8,9]$.

Pathogens, such as viruses, bacteria and parasites infect a wide range of hosts, such as human, farm/domestic animals and plants, and are responsible for high mortality, morbidity and/or damage [10, 11]. Pathogen sequences integrated into the host genome is not uncommon [12-15] and evolutionary sharing of sequence with the host has also been reported [16, 17]. A shared sequence is one where part or full-length of a pathogen protein is shared with one or more protein sequences of the host [18]. A pathogen sequence integrated into the host genome is herein considered as part of the host proteome, if expressed. Thus, shared sequences can be a result of pathogen integration into the host or otherwise. For example, the footprint of viruses in the evolution of the mammalian genome is thought to go back to at least tens of millions of years, in contrast to the earlier estimate of a few thousand. Taylor et al. (2010) confirmed that several groups of mammals, including marsupials that never colonized Africa, have had an association with filoviruses. This discovery of shared sequences between host-pathogen has important implications for the design of vaccines and drugs, diagnostics, disease surveillance and the study of emerging diseases, including unknown, potential host-pathogen interactions [19].

Shared sequences have been implicated in various cellular processes, which includes signalling, transduction, and protein stability [20-22]. These processes have been described to play a key role in pathogenicity of the host. Earlier studies of shared sequences or molecular mimicry have been based on similarity search for sequences of $k$-mer lengths of mostly penta-, hexa-, hepta-, or octapeptide (5-, 6-, 7- or 8-mer), and generally applied on a limited number of sequences of the pathogen of choice, such as Human gammaherpesvirus 4 (Epstein-Barr virus) [23], Human cytomegalovirus (HCMV) [24], Human immunodeficiency virus 1 (HIV-1) [18, 21], Poliovirus [25], West Nile virus (WNV) [22], Measles virus [26], Influenza A virus [16], Streptococcus species [27], Mycobacterium tuberculosis, Salmonella typhimurium, Klebsiella pneumonia, and Proteus mirabilis [28], among others. The availability of large data in the public repositories means much remains to be elucidated on shared sequences, which can further broaden our understanding of host-pathogen interactions [29, 30].

Existing alignment-based computational tools can be utilised for similarity search between host and pathogen sequences, such as BLAST [31], FASTA [32], and SSEARCH, among others. Limitations of these tools include i) the non-exhaustive nature of the search given the heuristic approach, which means not all $k$-mers may be compared to each other exhaustively, ii) gaps introduced in the alignment may break the collinearity of $k$-mers, iii) restriction on the number of hits returned (such as 20,000 for BLAST), iv) restriction on the number of queries per batch submission, and iv) time delay due to the iterations required to deal with the issues of (iii) and (iv) through a "break and conquer" approach, to deal with the large number of host and pathogen sequences available.

Herein, we describe a systematic bioinformatics approach for identification and characterization of shared sequences from big data. The approach is generic, and thus is potentially applicable to any pathogen and host combinations. A large number of protein sequences are available for pathogens and hosts in public repositories. The complete set of the identified shared sequences for a given host-pathogen will be termed as the share-ome. The identification, characterization and comparative analysis of multiple host-pathogen share-omes has important implications in the understanding of the evolution, structure and function of shared sequences. 


\section{Materials and methods}

The relevant bioinformatics tools, web servers, and tutorials described herein are collectively listed in Table 1 with the corresponding URLs.

A systematic bioinformatics approach is required to handle big data and mine for biological patterns and insights. The approach defined herein for the identification of the share-ome is a workflow that can be divided into four parts (Fig. 1): i) data collection, ii) data processing, iii) identification of the share-ome, and iv) share-ome analyses.

\section{Data collection}

Both nucleotide and protein sequences, available in abundance in public repositories (Table 2), are essential for the study of structure, function and evolution of shared sequences. Thus, a collection of all reported primary sequences is necessary for a comprehensive survey of the distribution and composition of shared sequences. The National Centre for Biotechnology Information (NCBI) (Table 1) Entrez Nucleotide (nt) and Protein (nr) databases provide a comprehensive collection of primary sequences [33]. When taxonomy is a selection criterion (such as all viruses), the NCBI Taxonomy database (Table 1) [33] is ideal for filtering of sequences at various ranks of taxonomy lineage. The number of sequences can grow exponentially when navigating from species to higher ranks of taxonomy in the database, such as from species, genus, family, superfamily, order, class, phylum, to superkingdom. As such, download via a Hypertext Transfer Protocol (HTTP) option will not be appropriate and maybe terminated due to timeout issues, while a File Transfer Protocol (FTP) browsing offers limited functionality to restrict the data to an Entrez query term. Thus, the NCBI application programme interface (API), Entrez E-utilities is ideal for retrieval of large datasets. Although nucleotide sequences are important for the study of shared sequences, the focus herein is on protein sequences, which can be compared with the cognate nucleotide sequences subsequently for underlying synonymous substitutions. Nonetheless, the approach for analysis of nucleotide sequences would be similar to that of proteins.

\section{Data cleaning and processing}

Removal of redundant and irrelevant sequences (including unknown, ambiguous, or outliers) is necessary to remove confounders in the identification of shared sequences. Public repositories often contain discrepancies and duplicate data entries [34-36]. Often, these are detected during the analysis step, such as when analysing the output of a multiple sequence alignment. A later detection of such sequences may necessitate a repeat of earlier data cleaning and pre-processing steps; thus, it is

Table 1 Tools, databases and tutorials relevant for the identification and characterization of the host-pathogen share-ome. All URLs were accessible as of January 2021

\begin{tabular}{|c|c|}
\hline Database, Tool, and Tutorial & URL \\
\hline NCBI Entrez Databases & http://www.ncbi.nlm.nih.gov \\
\hline NCBI Entrez Protein Database & http://www.ncbi.nlm.nih.gov/protein \\
\hline NCBI Entrez Taxonomy Database & http://www.ncbi.nlm.nih.gov/taxonomy \\
\hline STRING Viruses database & http://viruses.string-db.org/; version 11.0 \\
\hline CD-HIT & http://weizhongli-lab.org/cd-hit/ \\
\hline E-Utilities esearch-efetch & $\begin{array}{l}\text { https://www.ncbi.nlm.nih.gov/books/NBK25500/ } \\
\text { \#chapter1.Demonstration_Programs }\end{array}$ \\
\hline entrezEsearch & https://github.com/gwatiyapJ/SiMiLyG \\
\hline kmerslicer & https://github.com/gwatiyapJ/SiMiLyG \\
\hline Unipro UGENE tools & http://ugene.net/ \\
\hline UniProt Retrieving and ID Mapping tool & https://www.uniprot.org/uploadlists/ \\
\hline CateGorizer & https://www.animalgenome.org/tools/catego/ \\
\hline Unix utilities & https://unix.stackexchange.com/ \\
\hline Tutorial 1: Notes on how to use R for doing statistical analysis and graphics & https://cran.r-project.org/manuals.html \\
\hline $\begin{array}{l}\text { Tutorial 2: Unipro UGENE Manual Version 37, 2020. Consists of user guide to bioinformatics } \\
\text { tools for alignments, genome sequencing, data analysis, and amino acids sequence } \\
\text { visualization, among others. }\end{array}$ & $\begin{array}{l}\text { http://ugene.net/downloads/UniproUGENE_ } \\
\text { UserManual.pdf }\end{array}$ \\
\hline $\begin{array}{l}\text { Tutorial 3: User's guides on implementation for removing duplicates sequences and } \\
\text { generating representative sequences }\end{array}$ & $\begin{array}{l}\text { http://www.bioinformatics.org/cd-hit/cd-hit-user- } \\
\text { guide.pdf }\end{array}$ \\
\hline Tutorial 4: Webinar: Introduction to NCBI's E-utilities API & $\begin{array}{l}\text { https://www.youtube.com/watch?v=iCFWexp30o\&t= } \\
\text { 2561s }\end{array}$ \\
\hline
\end{tabular}




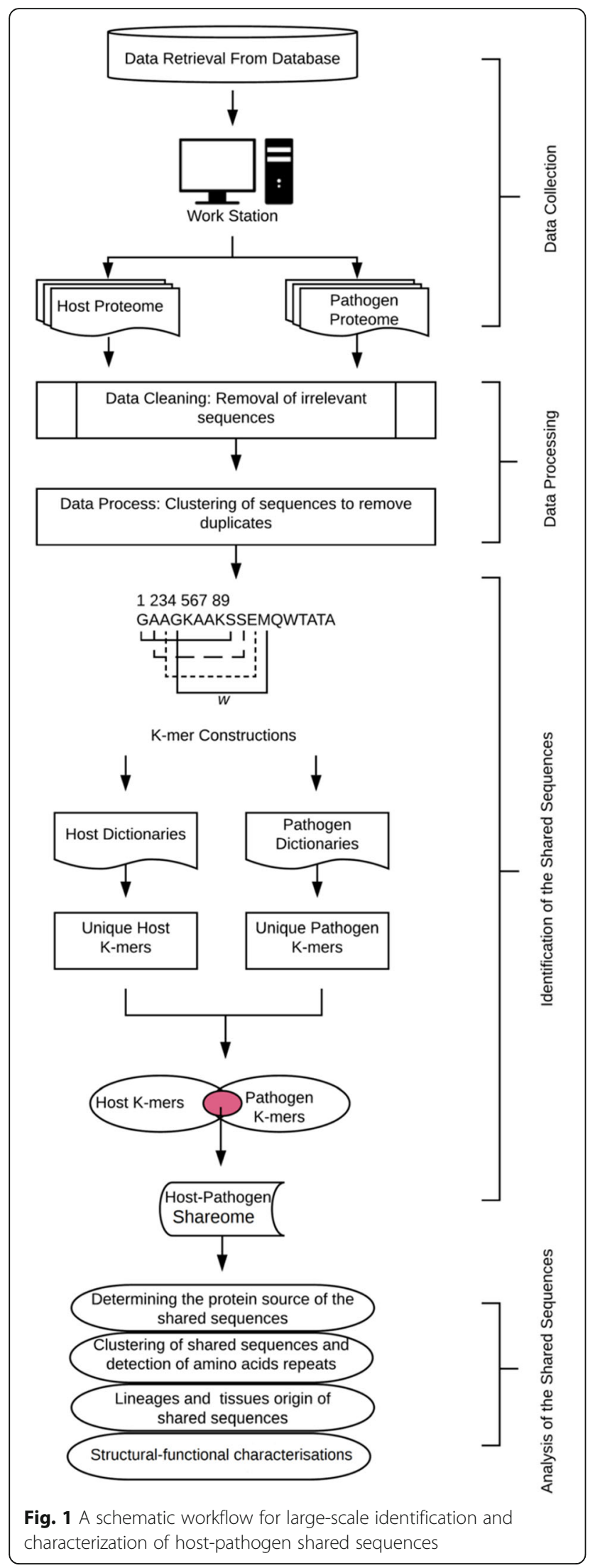

Table 2 Human pathogens/parasites and big data. The available number of nucleotide and protein sequence records at NCBI Entrez Databases (as of January 2021) are indicated for select groups of pathogens/parasites. It should be noted that not all the species that are part of the taxonomic groups listed here maybe pathogens/parasites of human

\begin{tabular}{lll}
\hline Pathogen/Parasite & \multicolumn{2}{l}{ Sequence Data (\# Records) } \\
\cline { 2 - 3 } & Nucleotides & Proteins \\
\hline Viruses & $3,554,899$ & $7,360,073$ \\
Bacteria & $68,010,589$ & $773,862,087$ \\
Archaea & 914,730 & $6,836,105$ \\
Fungi & $13,642,359$ & $25,043,777$ \\
Plasmodium & 567,181 & 662,147 \\
Amoebozoa & 802,451 & 317,693 \\
Trichomonas & 245,291 & 121,145 \\
Trypanosoma & 425,666 & 408,483 \\
Platyhelminthes (Flatworm) & $3,326,558$ & 787,530 \\
Nematodes & $4,321,847$ & $1,776,489$ \\
Acanthocephalans & 8863 & 2669 \\
Hirudinea (Leeches) & 255,634 & 52,331 \\
\hline
\end{tabular}

best to detect and filter these at the earliest. Examples of irrelevant sequences detected from supposedly a data of all viruses (Taxonomy Database ID: 10239) are shown in Table 3. The irrelevant hits may, for example, consist of sequences with no complete lineage information (i.e. no assigned viral species rank in the metadata, such as, only family rank), of unknown sample organism, that are synthetic construct or chimeric fusion protein, and/or of bacterial origin, mis-classified as viral or human data. One way of detecting these outliers at the data processing stage would be to extract the lineage field information in the metadata of each record and analyse for anomalies. Duplicate full-length or partial sequences can be filtered with the aid of the clustering tool, CD-HIT, which is capable of handling large datasets [37, 38].

Large-scale proteomics analyses usually present sample bias due to inadvertent collection of duplicate (full-length or partial identical match) or highly similar sequences, isolated from various geographical areas of limited catchment [39]. Removal of duplicate or similar sequences help, but may not be ideal to mitigate the bias. The redundancy may be a reflection of pathogen incidence in the ecosystem. Thus, it may be desired to analyse both the redundant and nonredundant datasets in most cases. However, for share-ome mapping and analysis, non-redundant dataset is preferred, with meta-data annotations from the redundant dataset retained. The annotations are retained because it is possible that, although the sequences are duplicates, the descriptions of the proteins are different. This maybe a result of user- 
Table 3 A sample of irrelevant hits identified through the data cleaning process. The irrelevant hits from a viral lineage search included those of missing/incomplete lineage information (unknown, unclassified or no species information) or of unrelated lineage (bacterial species) origin

\begin{tabular}{|c|c|c|}
\hline Protein ID & “Organism” field value & Remark \\
\hline CAA41747.1 & Retroviridae & Species information not available \\
\hline CAA41748.1 & Retroviridae & " \\
\hline AAB29320.1 & Tobamovirus & " \\
\hline AAB22506.1 & Orthohantavirus & " \\
\hline CAM83964.1 & unclassified Parechovirus & " \\
\hline 5AUM_D & Potyviridae & $"$ \\
\hline 2MLG_A & Fuselloviridae & $"$ \\
\hline 1BDE_A & Unknown & " \\
\hline 1Q3Z_A & Unknown & $"$ \\
\hline 3F2E_A & Rudivirus & $"$ \\
\hline ANM47321.1 & Streptococcus suis & Bacterial origin \\
\hline ANM47427.1 & Streptococcus suis & $"$ \\
\hline AAT65035.1 & Mycoplasma fermentans & $"$ \\
\hline AAT65057.1 & Mycoplasma fermentans & $"$ \\
\hline BAA94190.1 & Escherichia coli O157:H7 & " \\
\hline CAC83125.1 & Escherichia coli & " \\
\hline CAH23236.1 & Escherichia coli & $"$ \\
\hline CAH23267.1 & Escherichia coli & $"$ \\
\hline CAH23268.1 & Escherichia coli & " \\
\hline 4PJZ_A & Actinoplanes teichomyceticus & $"$ \\
\hline 4PKO_A & Actinoplanes teichomyceticus & " \\
\hline
\end{tabular}

dependent annotation (such as one description more detailed than the other) or are simply different protein names with the same sequence (related viral species sub-groups sharing the same sequence).

\section{Identification of a share-ome Construction of a k-mer dictionary}

$K$-mers are sequences of length $k$ that can comprise of either nucleotides or amino acids. Detection of shared sequences, as matched pairs between host and pathogen, involves exhaustive $k$-mer matching at a certain identity or similarity threshold. A sliding window approach to generate a $k$-mers dictionary (i.e. total repertoire of distinct $k$-mers for each of the pathogen and host datasets) can reveal the complexity of sequences [40], provide a varied classifier for the sequence by capturing several neighbouring residues [41], and describe short structural elements and functional group positions [42]. Although the size of the $k$-mer is user specified, there are, however, certain recommendations for the search of shared sequences. The BLAST algorithm uses short "words" to nucleate regions of similarity and the default size for a protein sequence is three amino acid residues, while size of 11 bases is the default for nucleotide sequences [43]. The $k$-mer size of one or two residues is inapplicable as they would result in random matches. The significance of the pair match would increase as $k$-mer size increases. The human immune system recognises peptides of length of 8-12 residues for binding to human leukocyte antigen (HLA) class I molecules $[44,45]$ and 13-25 residues for class II, with nine being the typical length for class I and the binding core of class II peptides [45, 46]. As such, it could be argued that the immune system is able to effectively discriminate between "self" and "nonself" at this length (9-mer). Although viruses represent "non-self", the shared sequences are a representation of "self" within "non-self", with consequences that typically benefit the virus (e.g. as amino acid repeats or decoys) and/or harm the host (e.g. through autoimmune reaction). The immune system may not be well adept in discriminating the so-called "self" within the "non-self" from "itself". Nonetheless, 9-mers appear to be the length of choice for antigen recognition over the evolutionary history of the adaptive (cellular) immune system 
in its defence against myriad of pathogens; indicating the need for a delicate balance between sensitivity and specificity.

The maximum $k$-mer size, if desired, can be the length of a given pathogen protein sequence of interest. It is noted that the longest consecutive, overlapping, identical $k$-mer match between viruses and human protein sequences can be in the range of hundredth amino acids, and this may expand to a longer length (possibly up to the protein size), particularly if one considers sequence similarity (using appropriate substitution matrix) rather than identity as the cut-off threshold for the match. Notably, the cytomegalovirus (CMV) virus codes for a protein that mimics the HLA molecule as a decoy [24].

A possible caveat of using longer $k$-mers is the likelihood of missing out shorter shared sequences. For example, a $k$-mer of nine (nonamer) would miss-out the detection of a shorter shared sequence, such as of six amino acids (6-mer), if the search criteria is a $100 \%$ match for the entire length of the 9-mer, and if the amino acids before or after the 6-mer (within the 9mer region) are dissimilar. This can be circumvented by using a similarity search approach instead. Thus, in general, shorter $k$-mers of reasonable lengths provide for a higher sensitivity coverage of shared sequences, while the overlaps between them would encompass the longer higher specificity $k$-mers.

One can generate $k$-mers for a given input FASTA file using our in-house tool "kmerslicer" (Table 1). The tool can accommodate any defined $k$-mer window size and annotates each $k$-mer with meta-data, such as the accession number(s) of the origin sequence(s) from which the $k$-mer was generated, and the beginning position of the $k$-mer in the sequence. A $k$-mer dictionary is generated for each of the host and the pathogen datasets, and duplicate k-mers are removed (however, meta-data annotations are retained) to reveal the distinct $k$-mers for each. The two k-mer dictionaries can be collectively referred to as a host-pathogen library, which can be mined for shared sequences; a library may comprise of multiple dictionaries of different $k$-mer lengths for the respective host and pathogen.

\section{Mapping of shared sequences}

Matching $k$-mers between the corresponding $k$-mer dictionaries of a given host-pathogen library is key to identifying shared sequences. This matching has to be done at a certain sequence identity or similarity threshold. The most stringent threshold would be $100 \%$ identity, where identical $k$-mers between the dictionaries are matched. The longer the $k$-mer length, the lesser the number of expected match hits. The more stringent the threshold, the more significant will be the shared sequences, in particular for longer $k$-mers. Thresholds of identity lower than $100 \%$ allow for inclusion of nucleotide or amino acid variations (outcome of mutation or recombination, for example) within the $k$-mer. Setting thresholds by use of identity are more stringent than similarity. Nonetheless, similarity thresholds are ideal to identify shared sequences that may no longer be identical, but conserved physico-chemically. This would help capture shared sequences that may have evolved since the point of integration, such as HIV-1 motifs [12], or are analogs of similar structure, such as a CMV protein (UL18), analogous to HLA [24].

\section{Share-ome analyses}

\section{Determining the protein source of the shared sequences}

Tracing the protein source of the shared sequences enables structure-function analysis of the share-ome. A given shared sequence can originate from multiple different protein sequences. The protein accession number is readily provided by the kmerslicer tool as the metadata information is stored alongside the $k$-mer sequence in the $k$-mer dictionary. The shared sequences and the corresponding protein accession data can be stratified to glean for information such as i) most abundant shared sequence (present in the most number of different proteins); ii) the least abundant shared sequence; it is possible that for specific host-pathogen relationships, the least abundant shared sequence could be in more than one protein; iii) pathogen species origin of the proteins containing the shared sequences (single or multispecies).

\section{Clustering of shared sequences and detection of amino acid repeats}

Proteins of host and pathogen can be highly represented and packed with shared sequences. Shared sequence representation (SSR) for a given protein is the fraction of the proteome-wide identified shared sequences that are present in the protein; i.e. the number of shared sequences present in a protein divided by the total number of shared sequences identified for the proteome, converted as a percentage:

$$
\operatorname{SSR}(p)=\left(\frac{n(p)}{n(S)}\right) \times 100
$$

where $n$ is the number of shared sequences present in a protein of interest, $p$, or the proteome, $S$.

Shared sequence packing (SSP) for a given protein is the length of the protein spanned by the identified shared sequences over the total length of the protein; i.e. the total contiguous length of the shared sequences 
present in a protein divided by the total length of the protein, converted as a percentage:

$$
\operatorname{SSP}(p)=\left(\frac{\sum_{i=1}^{n(p)} l_{i, p}}{L_{p}}\right) \times 100
$$

where $i$ is a given shared sequence, with $n$ as the number of shared sequences present in a protein of interest, $p$, and $l$ is the contiguous length of the shared sequences, while $L$ is the length of the protein, $p$. For example, a given viral protein, $p$ of length 100 amino acids and containing three nonamer shared sequences (spanning a contiguous length of 11 amino acids), originating from a viral proteome, $S$ comprising of 2537 nonamer shared sequences (share-ome), would have an SSR of $\sim 0.12 \%$ and an SSP of $\sim 11 \%$. It should be noted that when the shared sequences map to multiple contiguous regions in a protein, the sum of the lengths of these regions should be used for the SSP calculation. An SSP of 100\% for a protein would indicate that the full-length of the protein is shared, while an SSR of $100 \%$ for a protein would indicate that all the shared sequences of the proteome originated from the given single protein.

Shared sequences can also harbour amino acid repeats (AARs). These repeats can be either covering a subset or the full-length of the shared sequence. In terms of complexity, the repeats can be either simple (low-complexity) or complex; and in terms of distance, they can be tandem or non-tandem repeats. Identification of AARs can be carried out by use of the Dotplot plugin in the Unipro UGENE toolkit [47], which can handle big data. The Dotplot plugin provides a means for self- or nonself-comparison between two sequences, allowing identification and visualization, at gross level, of structural features of alignments, such as direct and inverted repeats (including palindromes), besides mutations, inversions, insertions, and deletions. A help webpage on how to use the Dotplot plugin is provided (URL in Table 1). AARs may represent important functional or structural motifs or domains, that can provide insight or footprint from molecular sequence on evolutionary mechanisms of host-pathogen interactions [48].

Proteins can also be littered with clusters of shared sequences (hotspots), which can be defined as regions in the protein that contain multiple (at least three or more) shared sequences, overlapping by at least one amino acid. The clusters can be of a minimum length of 11 amino acids to a significantly large size, such as $>100$ aa. Such hotspots possibly represent regions of high hostpathogen interaction activity and may be of important structural or functional implications. Presence of AARs within these hotspots can strengthen this assertion further [48].

AARs and hotspots are expected to exist in share-ome containing protein sequences, and AARs have been reported to play a key role in protein structure and function [49], such as molecular recognition and molecular assembly [48]. Additionally, abundance of repeats may be an indication of selective pressure exerted on the genome, signifying a conserved region among orthologous proteins, as observed in lysine, glutamic acid, proline, serine and alanine rich repeat proteins [50].

\section{Lineages and gene ontologies of shared sequences}

Determining the organismal lineage origin of the pathogen proteins that contain the shared sequences can reveal the identity of the pathogen species contributing to the share-ome; this information may help better understand the significance of the shared sequence and may provide relevant insights and/or implications of the pathogen to the host, in particular if no prior or limited interactions have been reported. The lineage information can be used to further characterize the pathogen shared sequences in terms of structural/functional comparisons, such as providing insights on homology and virulence factors, which can aid in understanding of pathogen mechanism of action [51], and/or reveal evolutionary trajectories of the pathogen variants and their replication mechanisms [52, 53]. Separately, analysis of gene ontologies of shared sequences is important to understand how and where the effect of the shared sequences maybe exerted. The gene ontologies can be studied for the host proteome (and for specific groups of pathogens, if gene ontology terms are well-established) through an enrichment analysis for cellular component by use of the Gene Ontology (GO) sever [54]. Additional characterization maybe performed on the identified shared sequences to better understand their function and structure, in particular host-defence implications.

\section{Functional-structural characterizations}

Numerous tools are available to develop bioinformatics approaches for detailed characterization of a mapped share-ome, in terms of structure and function. Approaches for functional characterization of pathogen and human molecular sequences have been described [55], facilitated by various tools that allow search for known functions reported in biological databases; and/or prediction of putative functions, modelled using various methods. Such prediction resources include protein family database (Pfam) [56], InterPro [57], conserved domain database (CDD) [58], and GO terms for enrichment analysis [59], among others. A specific aspect of function is the assessment of immunological relevance, given the autoimmune implications of the 
shared sequences. Both cellular and humoral immune responses are applicable to pathogen sequences. Humoral, B-cell epitopes can be predicted by use of tools [60, 61], such as BcePred, BEST, Pep-3D-Search, PepSurf, CED and PEPITO/BEPro, among others. Similarly, T-cell epitopes can be predicted by use of tools, such as CTLPred and NetCTLpan [60], among others.

Structural characterization may involve determining the 3D localisation of the shared sequence in the cognate protein [62] by use of a structure visualisation tool (such as VMD [63]), and assessing its surface accessibility and secondary structure by use of NetSurfP [64] or PDBePISA [65] and DSSP [66], respectively. Homology models may be built when a $3 \mathrm{D}$ structure is not available, either manually using Modeller or in an automated-fashion using Swiss-Model. Docking and 3D simulation maybe carried out to determine the binding efficacy of ligands using a number of tools available, such as AutoDock [67] and Gromacs [68].

\section{Results \\ Application: identification and characterization of Flaviviridae-human share-ome}

Flaviviridae is a family of small enveloped, positivestranded RNA viruses of 9000-13,000 bases [69]. Most are pathogenic to humans, other mammals and birds, and are chiefly spread by arthropod vectors (mainly ticks and mosquitoes). The family comprises of over 130 species grouped into four genera (Flavivirus, Hepacivirus, Pegivirus, and Pestivirus), with several unclassified species. The diseases associated with the family can range from asymptomatic to symptomatic, including hepatitis (hepaciviruses), haemorrhagic syndromes, fatal mucosal disease (pestiviruses), haemorrhagic fever, encephalitis, and the birth defect microcephaly (Zika virus). The Flavivirus genus is the largest with more than 70 viral species, and notably dengue virus alone poses risk to more than 3 billion people [70]. In this study, we applied the approach described herein to define and characterize the Flaviviridae-human share-ome. Flaviviridae sequences of dengue and West Nile viruses have been previously reported to be shared with other organisms [39, 71], such as mosquito (Aedes albopictus), rice (Oryza sativa (japonica cultivar-group)) and bacteria (Chromohalobacter salexigen, Acidiphilium cryptum JF-5, Actinomyces odontolyticus, Burkholderia ambifaria MC40-6, Burkholderia cepacia $A M M D$, and Methylobacterium extorquens $P A 1)$. The results herein provide insights that will help better understand the structure, function and evolution of Flaviviridae.

A total of 263,129 Flaviviridae and 1,245,872 human protein sequences were retrieved from the NCBI Entrez Protein (nr) database (as of June 2019 and May 2018, respectively) through the NCBI Taxonomy browser (ID:
"11050" for Flaviviridae) and E-Utilities esearch-efetch (ID: "9606" for human). Removing duplicate sequences by use of the CD-HIT tool [38] filtered out 49\% and $76 \%$ of the intially retrieved sequences of Flaviviridae and human, respectively. The use of the tool kmerslicer generated a 9-mer (nonamer) dictionary each from the Flaviviridae $(134,904)$ and human $(304,430)$ nonredundant sequences, respectively, resulting in 71,428 , 325 and 110,721,413 nonamers (redundant dataset). The choice of nonamer (9-mer) size was to balance between random and significant hits.

Removal of duplicate nonamers from each dictionary and cross-matching the remaining nonamers between the dictionaries resulted in a Flaviviridae-human shareome of 2537 nonamers (file size of $\sim 1.8 \mathrm{MB}$ ) at a threshold of $100 \%$ identity. Close inspection of the share-ome revealed that 110 nonamers matched to 79 unique protein records in the human dataset that appeared to be of non-human origin (with the "Organism" field value as "unknown", "unidentified" or name of a bacterial species). Further inspection revealed that two of the 79 were human sequences, six were chimeric fusion proteins (human and bacteria), and the remaining 71 were of bacterial origin (all were from Mesorhizobium delmotii). Such misclassification of protein records was not observed for the Flaviviridae dataset. Three of the 110 share-ome nonamers also matched to other human protein sequences, and thus, were retained, while the remaining 107 nonamers, as well as the matched 77 protein records were removed. This resulted in an eventual Flaviviridae-human share-ome of 2430 nonamers (file size of $\sim 1.8 \mathrm{MB}$ ) at a threshold of $100 \%$ identity (Supplementary Table 1). Although the share-ome represented a small fraction of the repertoire of Flaviviridae $(\sim 0.12 \%)$ and human $(\sim 0.013 \%)$ non-redundant nonamers $(2,107,979$ and $18,892,169$, respectively), the 2430 shared nonamers mapped to 16,946 Flaviviridae and 7506 human non-redundant protein sequences. The most abundant shared sequence "PVPPPRKKR" was present in 4268 viral and 13 human protein sequences; while "HHHHHHSSG" was present in 973 human and 10 viral protein sequences. As many as 181 shared sequences were least abundant, each present in only one protein of the virus and the host; this included "AAAAAA GLR" from Hepacivirus C "polyprotein" (specifically, from viral RNA dependent RNA polymerase region), shared with the human "EGF-containing fibulin-like extracellular matrix protein 1 isoform X1", "GENLYF QGM" shared between "Chain E, E Protein" of Zika virus and human "Chain A, E3 ubiquitin-protein ligase Mdm2", and "LGTVAVALG" shared between "polyprotein" of Theiler's disease-associated virus and human "spermatogenesis associated 3, isoform CRA a" protein, among others. The nonamer "AGCQRVGI 
S" was multi-species shared across Bovine viral diarrhea virus 1 (Pestivirus A), Bovine viral diarrhea virus 2 (Pestivirus B), and Bovine viral diarrhea virus 3 (Pestivirus $H$ ).

The "Second envelope protein (Fragment)" from Hepacivirus $C$ was most represented of shared sequences in the Flaviviridae proteome, with an SSR of 9.2\% (224 shared sequences). Similarly, for the human proteome, the sequence in the protein record "hCG2016179, isoform CRA_f" was the most represented, with an SSR of $\sim 8.7 \%$ (212 shared sequences); BLAST search revealed that this protein was a homolog to DnaJ protein. In contrast, the least represented proteins of the human and the Flaviviridae proteomes totalled to 4448 and 8618, respectively, with just a single shared sequence in each, and thus a negligible SSR of $\sim 0.04 \%$ for each protein. These proteins included "prostaglandin-endoperoxide synthase-1" and "papillary thyroid carcinoma-encoded protein" for human, among others; while for the Flaviviridae, they included "non-structural 2A-(NS2A)-protein" of Dengue virus 1, "envelope (E) protein" of Japanese encephalitis virus, and "non-structural 4B(NS4B)-protein" of GB virus, among others.

Assessment of SSPs revealed that the "LYST-interacting protein LIP6" in human was possibly the most packed of shared sequences, with an SSP value of $73.8 \%$. The least packed human protein was the "cytochrome P450c17, partial", among many others, with an SSP value of $\sim 1.8 \%$. Similarly, the "polyprotein, partial" of Bovine viral diarrhea virus 1 was possibly the most packed viral protein, with an SSP value of $~ 33.2 \%$ (calculated over the reported length of the partial polyprotein). The "non-structural 2A-(NS2A)-protein" of Dengue virus 1 , among many others, was the least packed, with an SSP of $\sim 0.3 \%$. There were several other hits with an SSP higher than those reported above, but were ignored from SSR, SSP and hotspot evaluations because record metadata review revealed that they were chimeric, synthetic construct, or modified protein (patent sequence). This shows that it may be difficult to remove all irrelevant sequences early on at the "data cleaning and processing" step (see Materials and Methods section). This is because it would require evaluating the meta-data of every single sequence record, coupled with domain expertise for correct interpretation, which can be a challenge for big data. Nonetheless, further checks herein suggested that the number of remaining irrelevant hits from human appeared limited. Moreover, the share-ome nonamers that these irrelevant proteins matched are also anticipated to be matched by other relevant proteins. Thus, the number of share-ome nonamers (2430) was expected to remain the same or change minimally. Separately, it should be noted that the polyprotein matches pose a question of whether to calculate the SSP over the entire length of the polyprotein or to calculate for each of the individual proteins matched within the polyprotein. Additionally, it should be considered that fusion proteins can also be natural, such as those composed of cellular and viral sequences, and thus, should not be filtered.

Analyses for AARs of length three to five amino acids at $100 \%$ identity among the 2430 nonamers of the shareome illustrated innumerable regions of repeats and inverted repeats within and between them (Fig. 2; Table 4; Supplementary Figure 1). Nearly 83\% (2026) of the shared sequences formed hotspots in viral proteins (Supplementary Table 2 provides a list of top 200 hotspots), each a cluster of at least three overlapping shared sequences covering a minimum length of 11 amino acids to a large region covering 160 amino acids (aa) of "p125 protein, partial" from Bovine viral diarrhea virus 1, with an SSP of $\sim 15.2 \%$. Similarly, for human, the longest hotspot covered a region of 95 amino acids, observed in the human protein, "LYST-interacting protein LIP6" (SSP, 73.8\%).

The shared nonamer sequences mapped to 125 species of Flaviviridae, including several with unclassified genus. The majority $(\sim 68 \%)$ of the shared sequences mapped to Hepacivirus $C$ species (Fig. 3). The West Nile, dengue and Zika viruses of the Flavivirus genus accounted for $\sim 11 \%, \sim 7 \%$, and $\sim 3 \%$, respectively, of the Flaviviridae protein sequences $(16,946)$ mapped by the shareome. Other notable species or groups of viruses only accounted for less than 1\% each, these included: Tick borne encephalitis virus, Japanese encephalitis virus, Pestiviruses, Pegivirus A, Kyasanur forest disease virus, and Yellow fever virus, among others. The Hepacivirus $C$ and Dengue viruses also had their various genotype

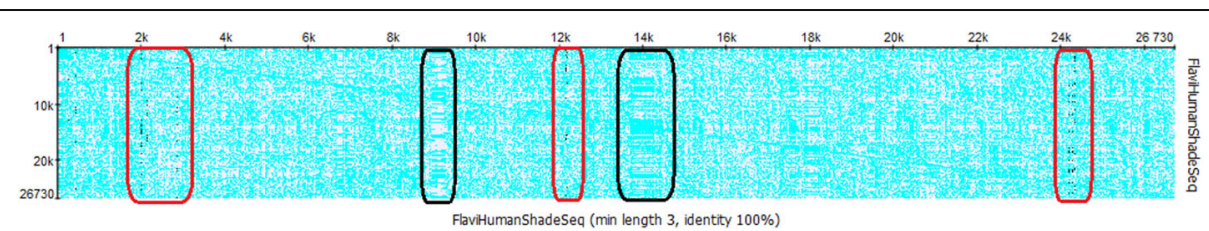

Fig. 2 Dot matrix of Flaviviridae-human shared sequences at window length of three amino acid residues. Multiple direct repeat regions (cyan areas) were identified in the dot plot. Well-defined regions of low-complexity are outlined in black, while well distinct inverted repeat regions are outlined in dark-red with prominent black dots as the indirect repeats 
Table 4 Sample of amino acid repeats (AARs) within the Flaviviridae-human shared sequences

\begin{tabular}{|c|c|c|c|c|c|c|c|c|c|c|c|}
\hline \multicolumn{6}{|c|}{ Direct Repeat } & \multicolumn{4}{|c|}{ Indirect Repeat } & \multirow{2}{*}{$\begin{array}{l}\text { Simple } \\
\text { Repeat } \\
\text { 9-mer }\end{array}$} & \multirow{2}{*}{$\begin{array}{l}\text { Non- Tandem } \\
\text { Repeat (NTR) } \\
\text { 9-mer }\end{array}$} \\
\hline $\begin{array}{l}\text { 3- } \\
\text { mer }\end{array}$ & $\begin{array}{l}\text { No. of } \\
\text { Matches }\end{array}$ & $\begin{array}{l}\text { 4- } \\
\text { mer }\end{array}$ & $\begin{array}{l}\text { No. of } \\
\text { Matches }\end{array}$ & 5-mer & $\begin{array}{l}\text { No. of } \\
\text { Matches }\end{array}$ & $\begin{array}{l}\text { 3- } \\
\text { mer }\end{array}$ & $\begin{array}{l}\text { No. of } \\
\text { Matches }\end{array}$ & $\begin{array}{l}\text { 4- } \\
\text { mer }\end{array}$ & $\begin{array}{l}\text { No. of } \\
\text { Matches }\end{array}$ & & \\
\hline$\overline{\text { GLL }}$ & 31 & AAAG & 14 & GGGSG & 28 & AAA & 96 & ELKQ & 6 & GGGGGGGGG & ENVKAKIQD \\
\hline GVD & 17 & GGGG & 47 & GSGGG & 27 & $A P A$ & 10 & LIKV & 3 & ннннннннн & ESTLHLVLR \\
\hline $\mathrm{HHH}$ & 313 & GIPP & 13 & ннннн & 222 & DGK & 7 & & & & GMQIFVKTL \\
\hline LLL & 293 & GRAA & 4 & LLLLA & 18 & GLL & 31 & & & & GRTLSDYNI \\
\hline LLS & 47 & НHнH & 222 & LLLLL & 80 & LLA & 48 & & & & HLVLRLRGG \\
\hline LPP & 23 & LIGL & 2 & LLLSL & 17 & LLL & 293 & & & & IQKESTLHL \\
\hline LVL & 40 & LLGL & 19 & PNPPKT & 4 & PLS & 16 & & & & KESTLHLVL \\
\hline PPQ & 16 & LLLL & 159 & PPPPP & 34 & $\mathrm{SAA}$ & 21 & & & & LHLVLRLRG \\
\hline PPR & 30 & LLSL & 26 & SHHHH & 25 & SPR & 12 & & & & NIQKESTLH \\
\hline RRL & 13 & LPVL & 10 & SSGLV & 5 & VAA & 17 & & & & STLHLVLRL \\
\hline
\end{tabular}

sequences well represented in the share-ome. Hepatitis $C$ virus genotype 1 accounted for $\sim 33 \%$ of the $\sim 68 \%$ Hepacivirus $C$ shared sequences in the share-ome, while Dengue virus serotype 1 accounted for $\sim 41 \%$ of the $\sim 7 \%$ of Dengue viruses.

Gene ontologies of the shared sequence were evaluated from the 7506 human protein (IDs) identified for the share-ome, which mapped to 2376 gene names in UniProt. However, for enrichment analysis, only 1132 records for cellular compartment GO Terms were annotated and retrieved for analysis. The 1132 GO terms were reduced mapped to 127 "GO_slim" terms (Fig. 4) by use of a GO Terms Classification Counter - CateGOrizer [72]. Notably, the high frequency terms implied localization of the proteins in the nucleus, plasma membrane and cytoskeleton. Studies have shown that nonstructural protein 3 (NS3) and NS5 of flaviruses interact with the cellular component cytoskeleton in human [73].

Biological process involvement of the 2376 human genes was evaluated by use of GeneMANIA Cytoscape plugin, which produced 2001 nodes and 215,897 edges (setting "biological processes" for the Gene Ontology term and "Homo sapiens" for source species) (Fig. 5). The most enriched biological process terms in the network were metabolism, cell communication and signal transduction, among others (data not shown). Network analyses of the nodes using the Network Analyzer of Cytoscape predicted 1879 hub genes, with node degree

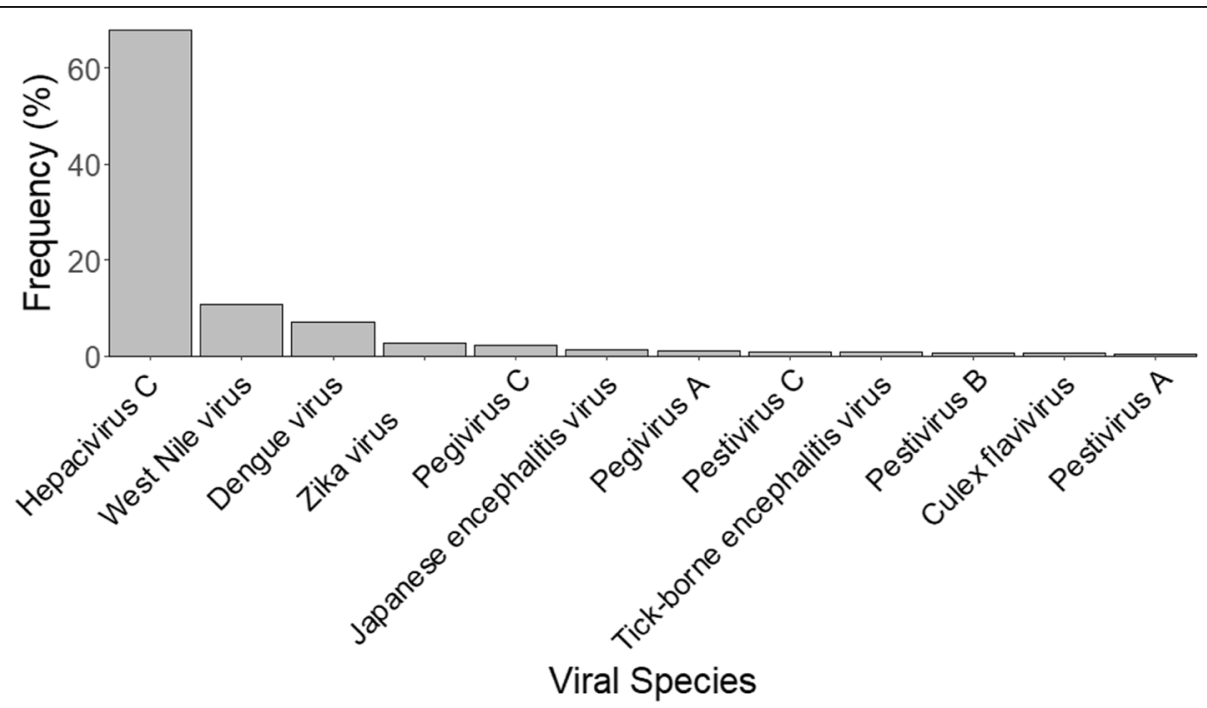

Fig. 3 Major Flaviviridae species that shared peptides of length nine (100\% identical) with human proteins 

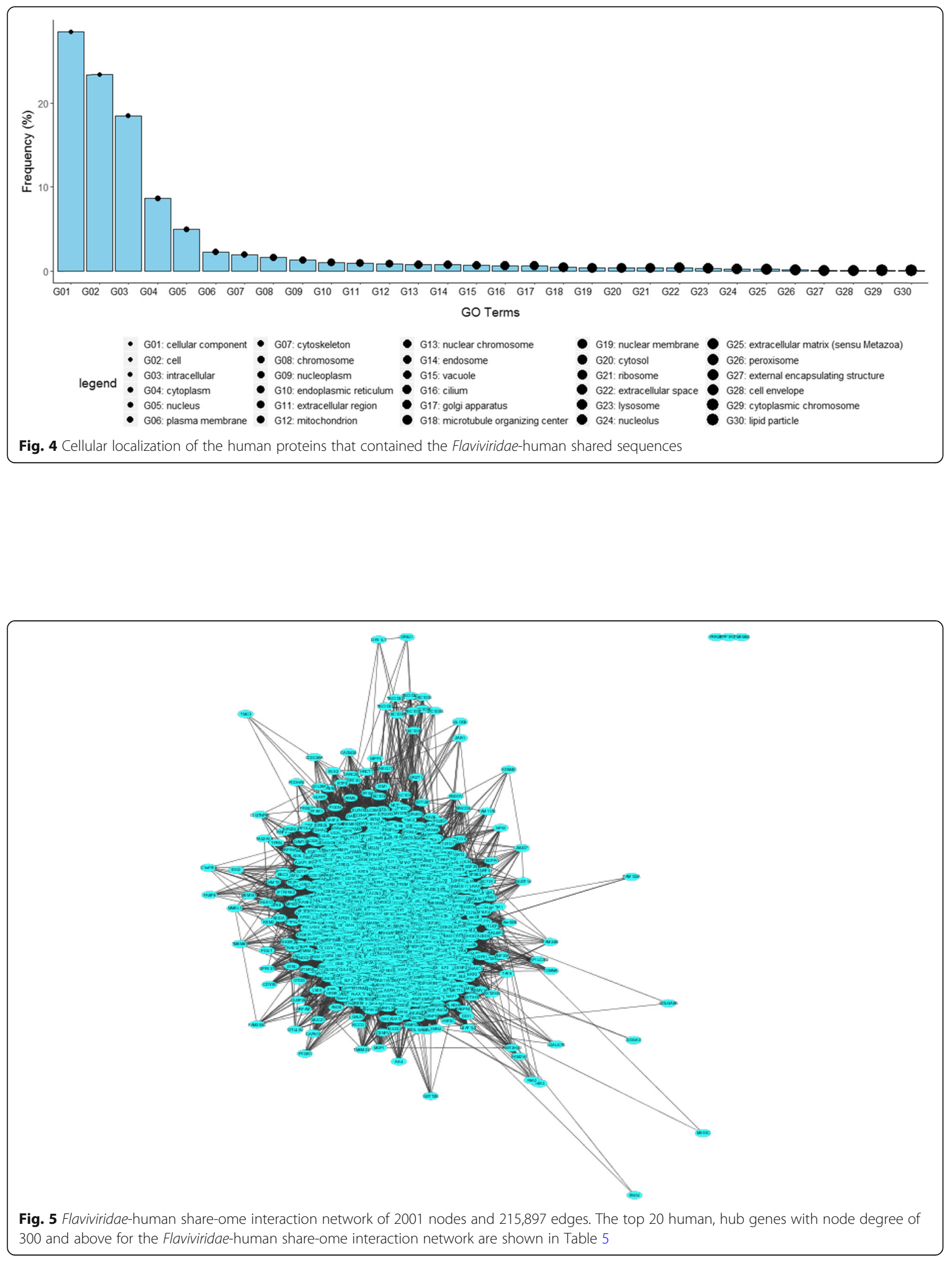
Table 5 Top 20 human, hub genes with node degree of 300 and above for the Flaviviridae-human share-ome interaction network

\begin{tabular}{|c|c|c|c|c|}
\hline Gene name & Degree & Betweenness Centrality & Closeness Centrality & Clustering Coefficient \\
\hline UBC & 1441 & 0.027056 & 0.781299 & 0.139379 \\
\hline APP & 665 & 0.004432 & 0.59898 & 0.166061 \\
\hline FN1 & 645 & 0.003141 & 0.595586 & 0.184236 \\
\hline XPO1 & 610 & 0.002835 & 0.588738 & 0.220372 \\
\hline AUTS2 & 606 & 0.002965 & 0.588912 & 0.181431 \\
\hline SRPK1 & 605 & 0.00213 & 0.588218 & 0.218477 \\
\hline CAND1 & 601 & 0.0021 & 0.585802 & 0.204786 \\
\hline CELF2 & 593 & 0.002288 & 0.58649 & 0.204714 \\
\hline TRIM28 & 579 & 0.002369 & 0.583236 & 0.199306 \\
\hline RBFOX1 & 576 & 0.002589 & 0.583577 & 0.18808 \\
\hline DAPK1 & 566 & 0.002433 & 0.581538 & 0.187911 \\
\hline PIK3R1 & 553 & 0.002085 & 0.578505 & 0.198063 \\
\hline DLG2 & 552 & 0.002489 & 0.577836 & 0.186907 \\
\hline EGFR & 551 & 0.002312 & 0.578673 & 0.186986 \\
\hline PRKG1 & 527 & 0.001923 & 0.575339 & 0.187856 \\
\hline SUMO1 & 526 & 0.001842 & 0.574676 & 0.221619 \\
\hline PPP2CA & 525 & 0.001574 & 0.574676 & 0.225096 \\
\hline IQGAP2 & 519 & 0.001925 & 0.573851 & 0.183431 \\
\hline EPS15 & 519 & 0.001614 & 0.571551 & 0.206002 \\
\hline KDM1A & 516 & 0.002118 & 0.571224 & 0.186227 \\
\hline
\end{tabular}

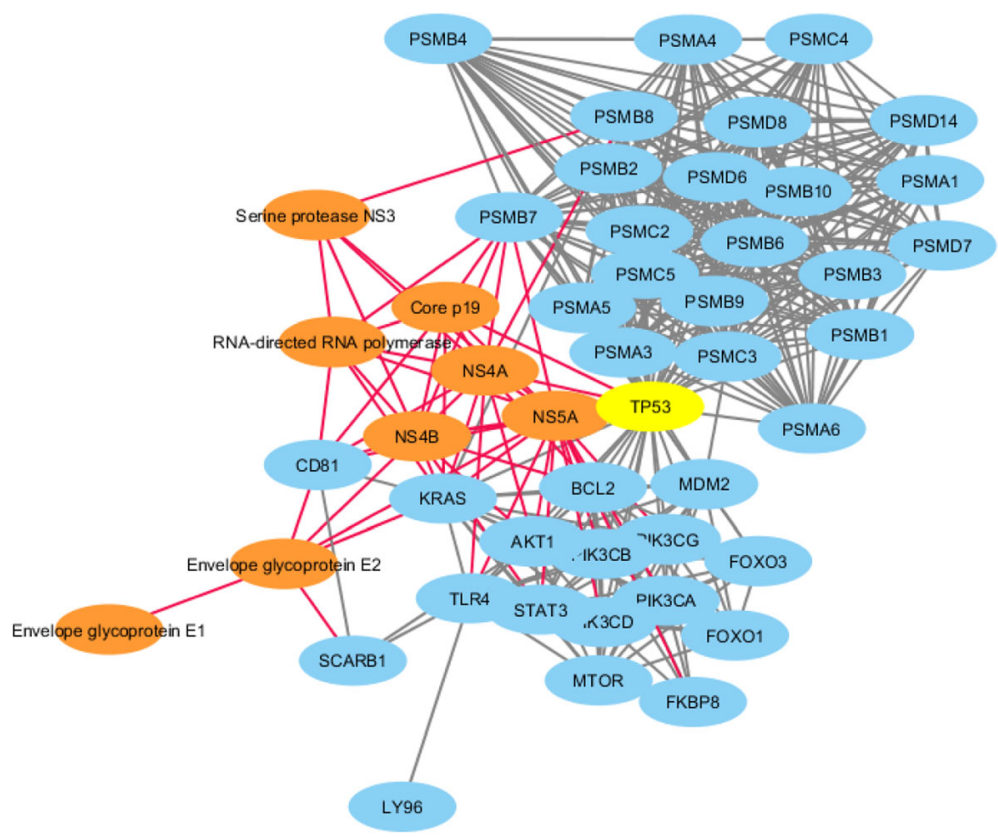

Fig. 6 Hepatitis C virus (HCV) genotype 1a-human protein-protein interaction (PPI) network. The HCV proteins associated with major hub, human proteins (TP53, PSMB7, and PSMB8, among others; Table 6). Orange nodes denote viral proteins with red edges linking to other nodes; blue nodes denote human proteins with grey edges linking to various nodes; and the yellow node denotes the hub protein with the highest degree of nodes. The TP53 is a hub connecting major nodes of the HCV genotype 1a-human PPI network 


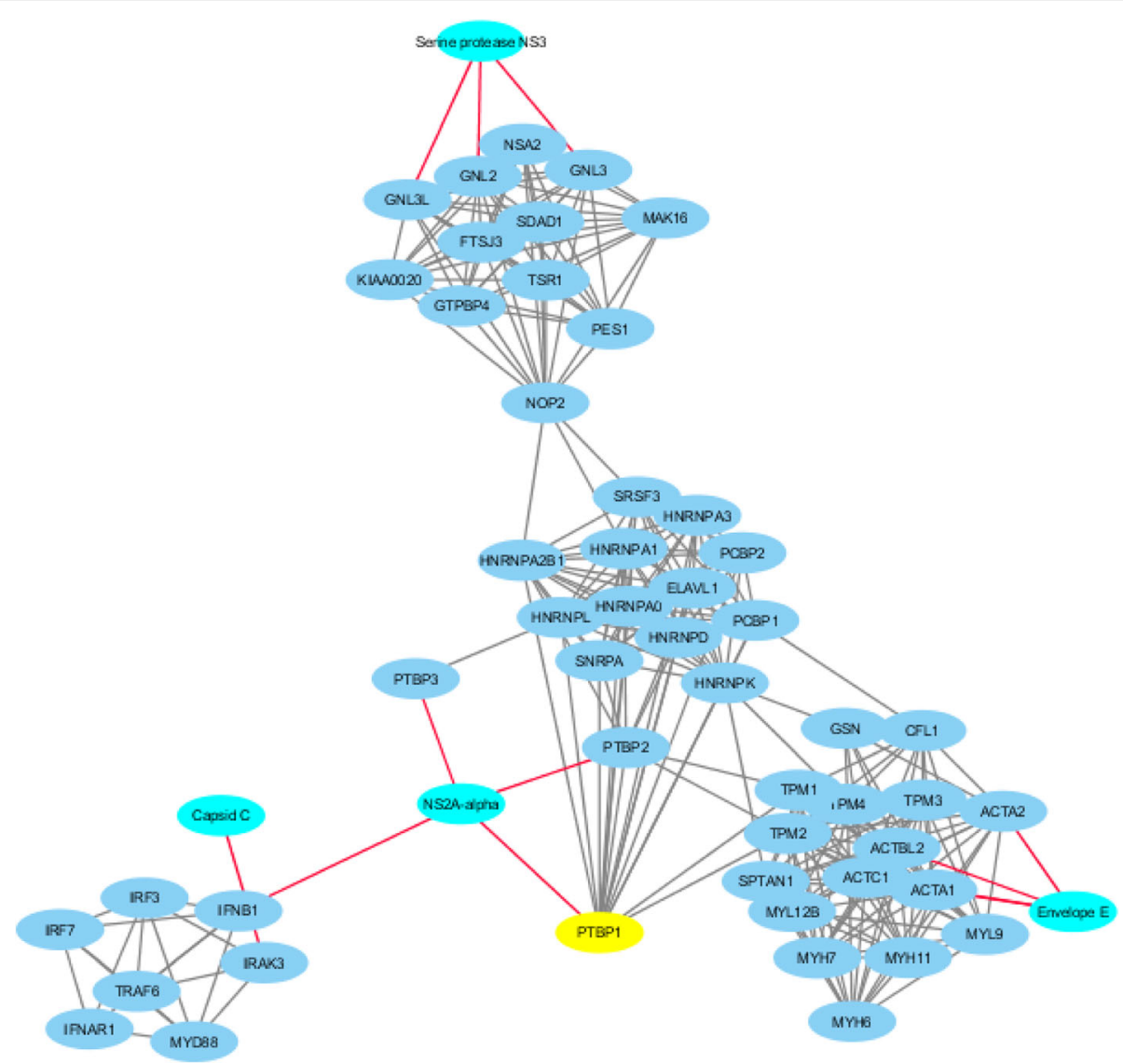

Fig. 7 Dengue virus type (DV) 2 (strain Jamaica/1409/1983)-human protein-protein interaction (PPI) network. The DV proteins associated with major hub, human proteins (PTBP1, ACTC1 and ACTA2, among others; Table 7). Cyan nodes denote viral proteins with red edges linking to other nodes; blue nodes denote human proteins with grey edges linking to various nodes; and the yellow node denotes the hub protein with the highest degree of nodes. The PTBP1 is a hub connecting major nodes, including NS2A-alpha, which connects other viral and human nodes to PTBP1 and to other nodes of the DV-human PPI network

Table 6 Top 10 hub genes with node degree of 22 and above for the Hepatitis C virus (HCV) genotype 1a-human protein-protein interaction network

\begin{tabular}{lllll}
\hline Gene Name & Degree & Betweenness Centrality & Closeness Centrality & Number of Directed Edges \\
\hline TP53 & 39 & 0.34606769 & 0.83928571 & 39 \\
PSMB7 & 27 & 0.07554848 & 0.67142857 & 27 \\
PSMB8 & 25 & 0.04383678 & 0.64383562 & 25 \\
PSMC3 & 23 & 0.00613026 & 0.6025641 & 23 \\
PSMA3 & 23 & 0.00613026 & 0.6025641 & 23 \\
PSMB3 & 22 & 0 & 0.59493671 & 22 \\
PSMB10 & 22 & 0 & 0.59493671 & 22 \\
PSMA4 & 22 & 0 & 0.59493671 & 22 \\
PSMD14 & 22 & 0 & 0.59493671 & 22 \\
PSMB4 & 22 & 0 & 0.59493671 & 22 \\
\hline
\end{tabular}


of 50 and above. The gene Ubiquitin $C$ (UBC) had the highest node degree of 1441 (Table 5) and it is reported to code for "polyubiquitin-C" protein [74]. Polyubiquitin- $\mathrm{C}$ is one of the sources of maintaining the ubiquitin homeostasis state under normal physiological conditions [75]. It also plays a key role in sustaining responses associated to UV irradiation, heat shock, oxidative stress and translational impairment. In addition, $\mathrm{UBC}$ being the gene with the highest node degree, where it interacts with a large population of genes, suggesting its importance as a possible share-ome mediator. The Ubiquitin (Ub) protein can be conjugated to select proteins to modulate their turnover and signalling. The protein Ub's broad role in cellular processes, such as protein trafficking, cell-cycle regulation, DNA repair, apoptosis and signal transduction, among others [75], have important clinical implications.

The Flaviviridae-human share-ome was functionally analysed for viral-host protein-protein interactions (PPI). The top 200 hotspot containing viral protein sequences (Supplementary Table 2) were subjected to this interaction analysis. Only 24 of these viral proteins were mapped to unique UniProt IDs, which were submitted to STRING Viruses database (Table 1) [76] for PPI. This returned a match to 10 viral organisms, two of which were further studied (match to Hepatitis $\mathrm{C}$ virus (HCV) genotype 1a (isolate $\mathrm{H}$ ) and Dengue virus (DV) type 2 (strain Jamaica/1409/1983)) as representative results of the analysis. Flaviviridae-human protein-protein interaction network for Hepatitis $C$ virus genotype 1a (Fig. 6) and Dengue virus type 2 (strain Jamaica/1409/1983) (Fig. 7) revealed eight and four viral proteins, respectively, involved in the interaction with human proteins. In the case of $\mathrm{HCV}$ genotype 1a, the eight viral proteins were "NS4A", "RNA-directed RNA polymerase", "Core p19", "Serine protease", "NS5A", "NS4B", "Envelope glycoprotein E2" and "Envelope glycoprotein E1", which were involved in the PPI with over 40 human proteins, directly or indirectly. The human TP53, which contained at least a shared sequence, was a hub protein with the highest node degree (Table 6). TP53, a "Cellular tumor antigen p53" protein, functions as a tumor suppressor in various types of tumors; regulates growth or apoptosis depending on the physiological conditions and cell type, among others [77]. The HCV NS5A, a non-structural protein occurs in two forms (p56 and p58), before being activated and released as NS5A and then localizes in the nuclear periplasmic membrane [78]. Notably, studies have shown association between NS5A and TP53, where the interaction appears to lead to transcriptional modulation of the p21/waf1 gene and is suggested to be one of the contributory factors towards $\mathrm{HCV}$-mediated pathogenesis. In the case of DV type 2 (strain Jamaica/ 1409/1983)-human PPI network (Fig. 7), the four viral proteins "Capsid C", "NS2A-alpha", "Envelope E", and "Serine protease NS3" were involved in the PPI with 43 human proteins. The human protein PTBP1, which contained at least a shared sequence, was a hub protein with the highest node degree (Table 7). PTBP1, a "Polypyrimidine tract-binding protein 1 ", functions as a regulating protein involved in mRNA splicing, especially in muscle cell differentiation. The polypyrimidine tract-binding protein (PTB) interacts with the regulatory sequences of positive-strand RNA viruses in the cytoplasm; PTB is translocated from the nucleus to the cytoplasm during DV infection [79]. Post infection, NS1 and NS3 of DV and human PTB are observed to co-localize with the endoplasmic reticulum marker calnexin. It has been shown that when PTB is not expressed, DV translation and replication are inhibited; PTB expression facilitates viral propagation. This suggests PTB and DV protein PPI in cytoplasmic environment plays a key role in dengue pathogenesis.

Additional literature mining for functional characterization of Flaviviridae-human shared sequences was carried out. Penta- and hexa-peptide (5- and 6-mer)

Table 7 Top 10 hub genes with node degree of 14 and above for Dengue virus type (DV) 2 (strain Jamaica/1409/1983)-human protein-protein interaction network

\begin{tabular}{lllll}
\hline Gene Name & Degree & Betweenness Centrality & Closeness Centrality & Number of Directed Edges \\
\hline PTBP1 & 16 & 0.26321534 & 0.46491228 & 16 \\
TPM2 & 16 & 0.10688075 & 0.39259259 & 16 \\
TPM4 & 16 & 0.03998649 & 0.36805556 & 16 \\
TPM1 & 16 & 0.10688075 & 0.39259259 & 16 \\
HNRNPK & 15 & 0.13451659 & 0.43089431 & 15 \\
HNRNPA1 & 14 & 0.1326909 & 0.43089431 & 14 \\
HNRNPA2B1 & 14 & 0.1326909 & 0.43089431 & 14 \\
ACTC1 & 14 & 0.01092874 & 0.31176471 & 14 \\
TPM3 & 14 & 0.00105224 & 0.31176471 & 14 \\
NOP2 & 14 & 0.35703919 & 0.3557047 & 14 \\
\hline
\end{tabular}


sharing between Zika virus (ZIKV, a fetopathogen and microcephaly-associated) polyprotein and human proteins linked/related to brain calcification, myelin, (de)myelination, and/or axonal neuropathies have been reported, and a number of the peptides were experimentally validated as immunopositive epitopes in human [80]. The study suggested cross-reactivity mechanism as a link between the infection and brain damage/neurodevelopmental disturbances observed in infants, as well as individuals with Guillain-Barré-like syndromes. Given that the search for longer shared sequences may miss shorter ones, a few of the peptides identified by [80] remained shared at nonamer level as part of the Flaviviridae-human share-ome identified herein. For example, the pentapeptide LGLTA in VAALGLTAV was shared between polyprotein of Zika virus and human "MOCO sulphurase C-terminal domain containing 1 (also known Mitochondrial amidoxime-reducing component 1)", "mitochondrial amidoxime-reducing component 1 precursor" and "mitochondrial amidoxime-reducing component 1 isoform X1" proteins (MOSC1). This MOSC1 is similar to human "Sulfite oxidase, mitochondrial", one of the microcephaly-related human proteins [81]. Another, pentapeptide LLGLL was observed in validated epitopes by [82], such as in RLLLLGLLLL and FLLGLLFFV, among others, which originated from viral proteins associated with autoimmune reactions, of the following fetopathogens: ZIKV, Human cytomegalovirus (HCMV), and Toxoplasma gondi [82]. Several additional nonapeptides (9-mers) containing the LLGLL motif were identified, all of which were observed in Hepacivirus $C$ (hepatitis C virus; HCV) "NS5" RNA-dependent RNA polymerase and shared with 20 human proteins, which included "chordin protein" and "desmoglein 3 (pemphigus vulgaris antigen), isoform CRA_a”, among others. The earlier study [82] did not identify any shared penta- or hexapeptide from Hepacivirus $C$, perhaps because they only studied 11 proteins of this virus (HCV) and restricted the search to human microcephaly-related proteins only, whereas herein all reported Flaviviridae and human protein sequences were compared. A literature search for "Hepacivirus $C$ and fetopathogenesis" was to no avail, and thus, this shared sequence match suggested a different role of the nonapeptide compared to the shorter penta- and hexapeptides that matched to human microcephaly-related proteins.

\section{Discussion}

Shared sequences represent a multi-faceted key to understanding the host-pathogen interactome, from functional, structural, evolutionary, and immunological perspectives [21, 83, 84]. Pathogens can interfere with the normal biological processes of their host, specifically by targeting the cell component, metabolism and/or metabolite [85], among others, facilitated by shared sequences. The bioinformatics approach presented herein provides a workflow and considerations to identify and characterize the host-pathogen share-ome, taking advantage of the big data in public repositories. Earlier studies were limited to identifying shared sequences for specific pathogen species of interest. While the workflow herein is essentially similar to the various works by others $[16$, $17,21,23,25]$, the generic methodology is described systematically, including details and various considerations, while providing additional new dimensions to certain aspects of the workflow. The current workflow was designed around the research goal of mapping and characterizing the share-ome. Comparison was done with the existing approaches, such as Peptide Match [86, 87], and where applicable, a similar strategy was applied, and new ones developed where lacking. This was particularly so in the area of structural-functional characterizations. As for mapping, the difference with earlier workflow was largely in the size of the $k$-mer utilised and also the scale of the sequences analysed. Taken together, this resulted in a new workflow, which enables a comprehensive and exhaustive mapping of shared sequences at big data scale between all reported pathogen sequences, at any given rank of taxonomy lineage, and all reported host sequences, at a chosen taxonomic rank. It is hoped that the work herein would facilitate other share-ome studies to be carried out rapidly, enabling comparative share-ome analyses.

Mapping of the share-ome has important implications towards the design of vaccines and drugs, and development of surveillance and diagnostic strategies against pathogens. Shared sequences predicted and/or validated to be immune relevant (e.g. as $\mathrm{B} / \mathrm{T}$-cell epitopes) may need to be filtered from inclusion as vaccine targets since they are shared with the host proteome [88]. Such sequences may escape immune recognition as a selfantigen or elicit an autoimmune response within the host through molecular mimicry [89-91]. A catalogue of the shared sequences can act as a reference for researchers involved in vaccine design. As for drug design, shared sequences are likely to be functionally and structurally important [92] and thus, expected to be evolutionarily conserved; therefore, inhibitory ligands may be designed against them to block pathogen activity. However, potential for side effect exists, given that they are also present in the host proteome. Thus, in general, shared sequences may be avoided from use as targets for inhibitory drug design. Nonetheless, careful evaluation of the pathogen and host proteins containing the shared sequence may offer insights on structural differences between them, which may abrogate the inhibitory ligand binding with the host protein, while being effective against the pathogen. Additionally, even if ligand binding 
ability is congruent with proteins of both pathogen and the host, there may be differences in the bioavailability of the host protein [93], and thus, reducing the possibility of side effects. Shared sequences may not meet the basic definition of a candidate diagnostic target, which are preferred to be conserved and specific to the organism of interest. Shared sequences may be conserved, but may not be specific; also, the level of conservation may not be at the desired threshold. Even if they meet the desired criteria for use as a diagnostic target, care must be taken to discriminate a false positive match with the host sequences, originating from remnant host cells in the sample. A catalogue of species relevant to a hostpathogen share-ome of interest, such as a list of all Flaviviridae species that share sequences with human, may reveal those that are not yet recognised as a threat to the host. Such species could be further evaluated for inclusion as candidates for surveillance under the list of emerging or priority pathogens. Additionally, ascertaining those that are known and medically important from the share-ome species catalogue may provide additional dimension to re-evaluate an existing priority pathogen list (PPL) [94, 95].

Herein, we described a systematic bioinformatics approach for identification and characterization of shared sequences from big data. Some of the big data challenges that may be encountered in executing the workflow include data download time (even with NCBI Entrez Eutilities API), deduplication of the data by use of CDHIT, dissection of the sequences into k-mers to generate the dictionaries, identification of AARs by use of UGENE, and mapping of the hotspots, among others. Resolution of these challenges include a combination of approaches, such as download of data when the bandwidth may be lesser occupied, such as over weekends, or getting access to a dedicated bandwidth, such as by use of a national Research Education Network (REN); a "break-and-conquer" approach by splitting the FASTA sequence file to various sizes to handle "out of memory" issues or by allocating a larger memory resource, or a combination of both. A cloud platform may be desired when access to an in-house high-performance computing is limited or is unavailable, provided a budget is at disposal to pay for the run-time; though the cost may be reasonable as it can be usage dependent. A workflow that is well-defined helps plan for these challenges accordingly and identify appropriate solutions, enabling a focus on the myriad of research questions possible from the data.

\section{Conclusion}

The workflow herein is generic and applicable to a broad variety of pathogens, such as viruses, bacteria, parasites, among others. The methodology significantly expands the breadth and depth of existing approaches. It enables the systematic screening and characterization of pathogen and host data which would otherwise be impossible to carry out experimentally, due to too many pathogen sequences (high pathogen diversity) and the large repertoire of the host proteome. It therefore significantly reduces the efforts and cost of experimentation, while providing for systematic screening. The Flaviviridae-human share-ome provided important structural and functional insights that help better understand the hostpathogen interaction of this important family of viruses, which poses an expanding threat to public health.

\section{Abbreviations}

aa: Amino acids; AARs: Amino acid repeats; API: Application programme interface; CDD: Conserved domain database; CD-HIT: Cluster Database at High Identity with Tolerance; CMV: Cytomegalovirus; DV: Dengue virus; GO: Gene Ontology; HCMV: Human cytomegalovirus; HCV: Hepatitis C virus (Hepacivirus C); HIV-1: Human immunodeficiency virus 1; HLA: Human leukocyte antigen; ID: Identification number; NCBI: National Centre for Biotechnology Information; NS: Non-structural protein; PDB: Protein Data Bank; Pfam: Protein family database; PPI: Protein-protein interaction; PPL: Priority pathogen list; REN: Research Education Network; RNA: Ribonucleic acid; SSP: Shared sequence packing; SSR: Shared sequence representation; UBC: Ubiquitin C; URL: Uniform Resource Locator; WNV: West Nile virus; ZIKV: Zika virus

\section{Supplementary Information}

The online version contains supplementary material available at https://doi. org/10.1186/s12864-021-07657-4.

\section{Additional file 1: Supplementary Figure 1. Dot matrix of Flaviviridae- human shared sequences at window lengths of three (A), four (B), and five $(C)$ amino acid residues. Multiple direct repeat regions (cyan areas) were identified in all the dot plots. A) and B) show well-defined regions of low-complexity (outlined in black). Inverted repeats are well distinct in ( $A$ and $B$ ) (regions outlined in dark-red with prominent black dots as the indirect repeats)}

Additional file 2: Supplementary Table 1. A catalogue of FlaviviridaeHuman share-ome nonapeptide sequences.

Additional file 3: Supplementary Table 2. Major clusters (hotspots) of Flaviviridae-Human shared sequences in proteins of Flaviviridae family viruses. This list includes Protein ID that may be chimeric, synthetic construct, or modified protein (patent sequence).

\section{Acknowledgements}

The authors thank Mr. Muhammad Farhan Sjaugi and Mr. Poh Yang Ming for their suggestions and help with the development of the in-

house computational tools used.

\section{About this supplement}

This article has been published as part of BMC Bioinformatics Volume 22 Supplement 3, 2021: 19th International Conference on Bioinformatics 2020 (InCoB2020): genomics. The full contents of the supplement are available online at https://bmcgenomics.biomedcentral.com/articles/supplements/ volume-22-supplement-3.

\section{Authors' contributions}

This work was carried out in collaboration with all authors. SAJ and AMK defined the workflow and wrote the manuscript. HSO and RHN critically assessed the work, contributed to the methodology development and the writing. All authors read and approved the final manuscript

Authors' information

Not applicable 


\section{Funding}

This work was supported by the National Economic Empowerment and Development Strategy (NEEDS) Assessment Intervention Fund of Nigeria, provided to Kaduna State University, Kaduna, Nigeria for Staff Development, as PhD Scholarship for SAJ to study in Malaysia. The computational resources and services used in this work were provided by Perdana University School of Data Sciences, Malaysia. AMK is supported by Perdana University, Malaysia, Bezmialem Vakif University, Turkey and The Scientific and Technological Research Council of Turkey (TÜBITAK). This publication/paper has been produced benefiting from the 2232 International Fellowship for Outstanding Researchers Program of TÜBITAK (Project No: 118C314). However, the entire responsibility of the publication/paper belongs to the owner of the publication/paper. The financial support received from TÜBITAK does not mean that the content of the publication is approved in a scientific sense by TÜBITAK. Publication of this supplement was funded by Perdana University. The funders had no role in the study design, data collection and analysis, decision to publish, or preparation of the manuscript.

\section{Availability of data and materials}

The datasets analysed herein are available at https://www.ncbi.nlm.nih.gov/ protein/?term=txid11050[Organism:exp] and https://www.ncbi.nlm.nih.gov/ protein/?term=txid9606[Organism:noexp] for Flaviviridae and human proteomes, respectively.

The data that support the findings of this study are available here: https://github.com/gwatiyapJ/shareomeHF

\section{Declarations}

Ethics approval and consent to participate

Not Applicable

\section{Consent for publication}

Not Applicable

\section{Competing interests}

We the authors declare that we have no competing interests in the research.

\section{Author details}

${ }^{1}$ Centre for Bioinformatics, School of Data Sciences, Perdana University, Damansara Heights, Kuala Lumpur 50490, Malaysia. ${ }^{2}$ Department of Biochemistry, Faculty of Science, Kaduna State University, Kaduna 800211, Nigeria. ${ }^{3}$ Beykoz Institute of Life Sciences and Biotechnology, Bezmialem Vakif University, Beykoz, Istanbul 34820, Turkey.

\section{Received: 14 March 2021 Accepted: 28 April 2021}

Pulished: 28 September 2021

\section{References}

1. Tagini F, Greub G. Bacterial genome sequencing in clinical microbiology: a pathogen-oriented review. Eur J Clin Microbiol Infect Dis. 2017;36(11):200720. https://doi.org/10.1007/s10096-017-3024-6.

2. Warrenfeltz S, Basenko EY, Crouch K, Harb OS, Kissinger JC, Roos DS, et al. EuPathDB: the eukaryotic pathogen genomics database resource. Methods Mol Biol. 2018;1757:69-113. https://doi.org/10.1007/978-1-4939-7737-6_5.

3. Van Goethem N, Descamps T, Devleesschauwer B, Roosens NHC, Boon NAM, Van Oyen $\mathrm{H}$, et al. Status and potential of bacterial genomics for public health practice: a scoping review. Implement Sci. 2019;14(1):79. https://doi.org/10.1186/s13012-019-0930-2

4. Pickett BE, Sadat EL, Zhang Y, Noronha JM, Squires RB, Hunt V, et al. ViPR: an open bioinformatics database and analysis resource for virology research. Nucleic Acids Res. 2012;40(D1):593-8. https://doi.org/10.1093/nar/gkr859.

5. Elbe S, Buckland-Merrett G. Data, disease and diplomacy: GISAID's innovative contribution to global health. Global Chall. 2017;1(1):33-46. https://doi.org/10.1002/gch2.1018.

6. Stephens ZD, Lee SY, Faghri F, Campbell RH, Zhai C, Efron MJ, et al. Big Data: Astronomical or Genomical? PLoS Biol. 2015;13(7):e1002195. https:// doi.org/10.1371/journal.pbio.1002195.

7. Rigden DJ, Fernandez XM. The 2018 nucleic acids research database issue and the online molecular biology database collection. Nucleic Acids Res. 2018;46(D1):1-7. https://doi.org/10.1093/nar/gkx1235.
8. Sintchenko V, Holmes EC. The role of pathogen genomics in assessing disease transmission. BMJ. 2015:350:1-13.

9. Bansal S, Chowell G, Simonsen L, Vespignani A, Viboud C. Big data for infectious disease surveillance and modeling. J Infect Dis. 2016;214:375-84. https://doi.org/10.1093/infdis/jiw400.

10. Dye C. After 2015: infectious diseases in a new era of health and development. Philos Trans R Soc B Biol Sci. 2014;369(1645):1-9. https://doi. org/10.1098/rstb.2013.0426.

11. Sarmah P, Dan MM, Adapa D, Sarangi Tk. A review on common pathogenic microorganisms and their impact on human health. Electron J Biol. 2018; 14(1):50-8. https://ejbio.imedpub.com/a-review-on-common-pathogenicmicroorganisms-and-their-impact-on-human-health.php?aid=22368. Accessed 21 Dec 2020.

12. Campbell EM, Hope TJ. HIV-1 capsid: the multifaceted key player in HIV-1 infection. Nat Rev Microbiol. 2015;13(8):471-83. https:/doi.org/10.1038/nrmicro3503.

13. Feschotte C, Gilbert C. Endogenous viruses: insights into viral evolution and impact on host biology. Nat Rev Genet. 2012;13(4):283-96. https://doi.org/1 $0.1038 /$ nrg3199.

14. Grow EJ, Flynn RA, Chavez SL, Bayless NL, Wossidlo M, Wesche DJ, et al. Intrinsic retroviral reactivation in human preimplantation embryos and pluripotent cells. Nature. 2015;522(7555):221-5. https:/doi.org/10.1038/nature14308.

15. Stoye JP. Studies of endogenous retroviruses reveal a continuing evolutionary saga. Nat Rev Microbiol. 2012;10(6):395-406. https://doi.org/1 $0.1038 /$ nrmicro2783

16. Lucchese G, Capone G, Kanduc D. Peptide sharing between influenza a H1N1 hemagglutinin and human axon guidance proteins. Schizophr Bull. 2014;40(2):362-75. https://doi.org/10.1093/schbul/sbs197.

17. Kanduc D, Stufano A, Lucchese G, Kusalik A. Massive peptide sharing between viral and human proteomes. Peptides. 2008;29(10):1755-66. https://doi.org/10.1016/j.peptides.2008.05.022.

18. Davey NE, Travé G, Gibson TJ. How viruses hijack cell regulation. Trends Biochem Sci. 2011;36(3):159-69. https://doi.org/10.1016/j.tibs.2 010.10 .002

19. Taylor DJ, Leach RW, Bruenn J. Filoviruses are ancient and integrated into mammalian genomes. BMC Evol Biol. 2010;10(1):193. https://doi.org/10.11 86/1471-2148-10-193.

20. Gouw M, Michael S, Sámano-Sánchez H, Kumar M, Zeke A, Lang B, et al. The eukaryotic linear motif resource - 2018 update. Nucleic Acids Res. 2018; 46(D1):D428-34. https://doi.org/10.1093/nar/gkx1077.

21. Lucchese G, Stufano A, Calabro M, Kanduc D. Charting the peptide crossreactome between HIV-1 and the human proteome. Front Biosci (Elite Ed). 2011;3:1385-400. https://doi.org/10.2741/e341.

22. Capone G, Pagoni M, Delfino AP, Kanduc D. Evidence for a vast peptide overlap between West Nile virus and human proteomes. J Basic Microbiol. 2012;52:1-8. https://doi.org/10.1002/jobm.201200204

23. Capone G, Calabrò M, Lucchese G, Fasano C, Girardi B, Polimeno L, et al. Peptide matching between Epstein-Barr virus and human proteins. Pathog Dis. 2013;69(3):205-12. https://doi.org/10.1111/2049$632 X .12066$.

24. Carrillo-Bustamante P, Keşmir C, de Boer RJ. Virus encoded MHC-like decoys diversify the inhibitory KIR repertoire. PLoS Comput Biol. 2013;9:1-13.

25. Capone G, Novello G, Bavaro SL, Fasano C, Polito AN, Kanduc D. A quantitative description of the peptide sharing between poliovirus and Homo sapiens. Immunopharmacol Immunotoxicol. 2012;34(5):779-85. https://doi.org/10.3109/08923973.2012.654610.

26. Kanduc D. Measles virus hemagglutinin epitopes are potential hotspots for crossreactions with immunodeficiency-related proteins. Future Microbiol. 2015;10(4):503-15. https://doi.org/10.2217/fmb.14.137.

27. Trost B, Kusalik A, Lucchese G, Kanduc D. Bacterial peptides are intensively present throughout the human proteome. Self Nonself. 2010;1(1):71-4. https://doi.org/10.4161/self.1.1.9588.

28. Trost B, Lucchese G, Stufano A, Bickis M, Kusalik A, Kanduc D. No human protein is exempt from bacterial motifs, not even one. Self Nonself. 2010; 1(4):328-34. https://doi.org/10.4161/self.1.4.13315.

29. Sheng Tao Z, Rui L, Xia Z, CanHua H, YuQuan W. Viral proteomics: the emerging cutting-edge of virus research. Sci China Life Sci. 2011;54:502-12.

30. Maxwell KL, Frappier L. Viral proteomics. Microbiol Mol Biol Rev. 2007;71(2): 398-411. https://doi.org/10.1128/MMBR.00042-06.

31. Camacho C, Coulouris G, Avagyan V, Ma N, Papadopoulos J, Bealer K, et al. BLAST+: architecture and applications. BMC Bioinformatics. 2009;10(1):421. https://doi.org/10.1186/1471-2105-10-421. 
32. Pearson WR. An introduction to sequence similarity ("homology") searching. Curr Protoc Bioinformatics. 2013;Chapter 3:Unit3.1. https://doi.org/10.1002/ 0471250953.bi0301s42.

33. Agarwala R, Barrett T, Beck J, Benson DA, Bollin C, Bolton E, et al. Database resources of the National Center for biotechnology information. Nucleic Acids Res. 2016:44:D7-19.

34. Chen Q, Zobel J, Verspoor K. Duplicates, redundancies and inconsistencies in the primary nucleotide databases: a descriptive study. Database. 2017; 2017:1-16. https://doi.org/10.1093/database/baw163.

35. Subramaniy $V$, Pandian SC. A complete survey of duplicate record detection using data mining techniques. Inf Technol J. 2012;11(8):941-5. https://doi. org/10.3923/itj.2012.941.945.

36. Koh J, Lee M, Khan A, Tan PT, Brusic V. Duplicate detection in biological data using association rule mining. In European Workshop on Data Mining and Text Mining in Bioinformatics. 2004. https://www.semanticscholar.org/ paper/Duplicate-Detection-in-Biological-Data-using-Rule-Koh-Lee/ ebf0d6c78174c2bfe69efa74369645bc90e7835d. Accessed 21 Dec 2020

37. Li W, Godzik A. Cd-hit: a fast program for clustering and comparing large sets of protein or nucleotide sequences. Bioinformatics. 2006;22(13):1658-9. https://doi.org/10.1093/bioinformatics/btl158.

38. Fu L, Niu B, Zhu Z, Wu S, Li W. CD-HIT: accelerated for clustering the nextgeneration sequencing data. Bioinformatics. 2012;28(23):3150-2. https://doi. org/10.1093/bioinformatics/bts565.

39. Khan AM, Miotto O, Nascimento EJM, Srinivasan KN, Heiny AT, Zhang GL, et al. Conservation and variability of dengue virus proteins: implications for vaccine design. PLoS Negl Trop Dis. 2008;2(8):1-7. https://doi.org/10.1371/ journal.pntd.0000272.

40. Anvar SY, Khachatryan L, Vermaat M, Galen MV, Pulyakhina I, Ariyurek Y, et al. Determining the quality and complexity of next-generation sequencing data without a reference genome. Genome Biol. 2014;15(12): 555. https://doi.org/10.1186/s13059-014-0555-3.

41. Jiang J, Wang N, Chen P, Zheng C, Wang B. Prediction of protein hotspots from whole protein sequences by a random projection ensemble system. Int J Mol Sci. 2017;18(7):1-13. https://doi.org/10.3390/ijms18071543.

42. Yang L, Orenstein Y, Jolma A, Yin Y, Taipale J, Shamir R, et al. Transcription factor family-specific DNA shape readout revealed by quantitative specificity models. Mol Syst Biol. 2017;13:1-14. https://doi.org/10.15252/msb.20167238.

43. Altschul SF. BLAST Algorithm. eLS; 2014. https://doi.org/10.1002/978047001 5902.a0005253.pub2.

44. Stauss HJ. Peptides feeling groovy. Curr Biol. 1991;1(5):328-30. https://doi. org/10.1016/0960-9822(91)90102-3.

45. Parham P. Oh to be twenty seven again. Nature. 1991;351(6327):523. https:// doi.org/10.1038/351523a0.

46. Doytchinova IA, Flower DR. In Silico identification of Supertypes for class II MHCs. J Immunol. 2005;174(11):7085-95. https://doi.org/10.4049/jimmunol.1 74.11.7085.

47. Okonechnikov K, Golosova O, Fursov M, Varlamov A, Vaskin Y, Efremov I, et al. Unipro UGENE: a unified bioinformatics toolkit. Bioinformatics. 2012; 28(8):1166-7. https://doi.org/10.1093/bioinformatics/bts091.

48. Luo $\mathrm{H}$, Nijveen $\mathrm{H}$. Understanding and identifying amino acid repeats. Brief Bioinform. 2014;15(4):582-91. https://doi.org/10.1093/bib/bbt003.

49. Barik S. Amino acid repeats avert mRNA folding through conservative substitutions and synonymous codons, regardless of codon bias. Heliyon. 2017;3(12):e00492. https://doi.org/10.1016/j.heliyon.2017.e00492.

50. Kumar AS, Sowpati DT, Mishra RK. Single amino acid repeats in the proteome world: structural, functional, and evolutionary insights. PLoS One. 2016;11(11):1-19. https://doi.org/10.1371/journal.pone.0166854.

51. Wallqvist A, Memišević V, Zavaljevski N, Pieper R, Rajagopala SV, Kwon K, et al. Using host-pathogen protein interactions to identify and characterize Francisella tularensis virulence factors. BMC Genomics. 2015;16(1):1-18. https://doi.org/10.1186/s12864-015-2351-1.

52. Forterre $P$, Krupovic M, Prangishvili D. Cellular domains and viral lineages. Trends Microbiol. 2014;22(10):554-8. https://doi.org/10.1016/j.tim.2014.07.004.

53. Durzyńska J, Goździcka-Józefiak A. Viruses and cells intertwined since the dawn of evolution. Virol J. 2015;12(1):169. https://doi.org/10.1186/s12985-015-0400-7.

54. Kim H-I, Kim J-H, Park Y-J. Transcriptome and gene ontology (GO) enrichment analysis reveals genes involved in biotin metabolism that affect I-lysine production in Corynebacterium glutamicum. Int J Mol Sci. 2016: 17(3):353. https://doi.org/10.3390/ijms17030353.

55. Khan AM, Miotto O, Heiny AT, Salmon J, Srinivasan KN, Nascimento E, et al. A systematic bioinformatics approach for selection of epitope-based vaccine targets. Cell Immunol. 2007;244(2):141-7. https://doi.org/10.1016/j. cellimm.2007.02.005.

56. Finn RD, Coggill P, Eberhardt RY, Eddy SR, Mistry J, Mitchell AL, et al. The Pfam protein families database: towards a more sustainable future. Nucleic Acids Res. 2016;44(D1):D279-85. https://doi.org/10.1093/nar/gkv1344.

57. Mulder NJ, Apweiler R, Attwood TK, Bairoch A, Bateman A, Binns D, et al. InterPro: an integrated documentation resource for protein families, domains and functional sites. Brief Bioinform. 2002;3(3):225-35. https://doi. org/10.1093/bib/3.3.225

58. Marchler-Bauer A, Zheng C, Chitsaz F, Derbyshire MK, Geer LY, Geer RC, et al. CDD: conserved domains and protein three-dimensional structure. Nucleic Acids Res. 2013;41:348-52.

59. Eden E, Navon R, Steinfeld I, Lipson D, Yakhini Z. GOrilla: a tool for discovery and visualization of enriched $\mathrm{GO}$ terms in ranked gene lists. BMC Bioinformatics. 2009:10:1-7.

60. Soria-Guerra RE, Nieto-Gomez R, Govea-Alonso DO, Rosales-Mendoza S. An overview of bioinformatics tools for epitope prediction: implications on vaccine development. J Biomed Inform. 2015;53:405-14. https://doi.org/10.1 016/j.jbi.2014.11.003.

61. Sun P, Ju H, Liu Z, Ning Q, Zhang J, Zhao X, et al. Bioinformatics resources and tools for conformational B-cell epitope prediction. Comput Math Methods Med. 2013;2013:1-11. https://doi.org/10.1155/2013/943636.

62. Raval A, Piana S, Eastwood MP, Dror RO, Shaw DE. Refinement of protein structure homology models via long, all-atom molecular dynamics simulations. Proteins. 2012;80(8):2071-9. https://doi.org/10.1002/prot.24098.

63. Humphrey W, Dalke A, Schulten K. VMD: visual molecular dynamics. J Mol Graph. 1996;14(1):33-8. https://doi.org/10.1016/0263-7855(96)00018-5.

64. Klausen MS, Jespersen MC, Nielsen H, Jensen KK, Jurtz VI, Sønderby CK, et al. NetSurfP-2.0: Improved prediction of protein structural features by integrated deep learning. Proteins Struct Funct Bioinforma. 2019;87:520-7. https://doi.org/10.1002/prot.25674.

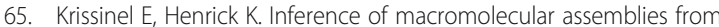
crystalline state. J Mol Biol. 2007;372(3):774-97. https://doi.org/10.1016/j. jmb.2007.05.022.

66. Kabsch W, Sander C. Dictionary of protein secondary structure: pattern recognition of hydrogen-bonded and geometrical features. Biopolymers. 1983;22(12):2577-637. https://doi.org/10.1002/bip.360221211.

67. Morris GM, Huey R, Lindstrom W, Sanner MF, Belew RK, Goodsell DS, et al. AutoDock4 and AutoDockTools4: automated docking with selective receptor flexibility. J Comput Chem. 2009;30(16):2785-91. https://doi.org/10.1002/jcc.21256.

68. Abraham MJ, Murtola T, Schulz R, Páll S, Smith JC, Hess B, et al. GROMACS: high performance molecular simulations through multi-level parallelism from laptops to supercomputers. SoftwareX. 2015;1-2:19-25. https://doi. org/10.1016/j.softx.2015.06.001.

69. Simmonds P, Becher P, Bukh J, Gould EA, Meyers G, Monath T, et al. ICTV virus taxonomy profile: Flaviviridae. J Gen Virol. 2017;98(1):2-3. https://doi. org/10.1099/jgv.0.000672.

70. Murray NEA, Quam MB, Wilder-Smith A. Epidemiology of dengue: past, present and future prospects. Clin Epidemiol. 2013;5:299-309. https://doi. org/10.2147/CLEP.S34440.

71. Koo QY, Khan AM, Jung K-O, Ramdas S, Miotto O, Tan TW, et al. Conservation and variability of West Nile virus proteins. PLoS One. 2009;4(4): e5352. https://doi.org/10.1371/journal.pone.0005352.

72. Hu Z-L, Bao J, Reecy JM. CateGOrizer: a web-based program to batch analyzegene ontology classification categories. Online J Bioinform. 2008b:9(2):108-12.

73. Le Breton M, Meyniel-Schicklin L, Deloire A, Coutard B, Canard B, de Lamballerie $X$, et al. Flavivirus NS3 and NS5 proteins interaction network: a high-throughput yeast two-hybrid screen. BMC Microbiol. 2011;11(1):234 https://doi.org/10.1186/1471-2180-11-234.

74. Wiborg O, Pedersen MS, Wind A, Berglund LE, Marcker KA, Vuust J. The human ubiquitin multigene family: some genes contain multiple directly repeated ubiquitin coding sequences. EMBO J. 1985;4(3):755-9. https://doi. org/10.1002/j.1460-2075.1985.tb03693.x.

75. Radici L, Bianchi M, Crinelli R, Magnani M. Ubiquitin C gene: structure, function, and transcriptional regulation. Adv Biosci Biotechnol. 2013;04(12): 1057-62. https://doi.org/10.4236/abb.2013.412141.

76. Cook HV, Doncheva NT, Szklarczyk D, von Mering C, Jensen LJ. Viruses.STRING: a virus-host protein-protein interaction database. Viruses. 2018;10:1-11.

77. Ghosh A, Stewart D, Matlashewski G. Regulation of human p53 activity and cell localization by alternative splicing. Mol Cell Biol. 2004;24(18):7987-97. https://doi.org/10.1128/MCB.24.18.7987-7997.2004. 
78. Majumder M, Ghosh AK, Steele R, Ray R, Ray RB. Hepatitis C virus NS5A physically associates with $\mathrm{p} 53$ and regulates $\mathrm{p} 21 /$ waf1 gene expression in a p53-dependent manner. J Virol. 2001;75(3):1401-7. https://doi.org/10.1128/ JVI.75.3.1401-1407.2001.

79. Agis-Juárez RA, Galván I, Medina F, Daikoku T, Padmanabhan R, Ludert JE, et al. Polypyrimidine tract-binding protein is relocated to the cytoplasm and is required during dengue virus infection in Vero cells. J Gen Virol. 2009; 90(12):2893-901. https://doi.org/10.1099/vir.0.013433-0.

80. Lucchese G, Kanduc D. Zika virus and autoimmunity: From microcephaly to Guillain-Barré syndrome, and beyond. Autoimmun Rev. 2016;15(8):801-8. https://doi.org/10.1016/j.autrev.2016.03.020.

81. Tan WH, Eichler FS, Hoda S, Lee MS, Baris H, Hanley CA, et al. Isolated sulfite oxidase deficiency: a case report with a novel mutation and review of the literature. Pediatrics. 2005;116(3):757-66. https://doi.org/10.1542/peds.2004-1897.

82. Lucchese G, Kanduc D. Minimal immune determinants connect Zika virus, human Cytomegalovirus, and toxoplasma gondii to microcephaly-related human proteins. Am J Reprod Immunol. 2017;77(2):e12608. https://doi.org/1 $0.1111 /$ aji.12608.

83. Kanduc D. Proteome-wide epstein-barr virus analysis of peptide sharing with human systemic lupus erythematosus autoantigens. Isr Med Assoc J. 2019;21(7):444-8.

84. Kanduc D. The comparative biochemistry of viruses and humans: an evolutionary path towards autoimmunity. Biol Chem. 2019;400(5):629-38. https://doi.org/10.1515/hsz-2018-0271.

85. Welch MD. Why should cell biologists study microbial pathogens? Mol Biol Cell. 2015;26(24):4295-301. https://doi.org/10.1091/mbc.e15-03-0144.

86. Chen C, Li Z, Huang H, Suzek BE, Wu CH. A fast peptide match service for UniProt knowledgebase. Bioinformatics. 2013;29(21):2808-9. https://doi.org/1 0.1093/bioinformatics/btt484.

87. Bavaro SL, Calabrò M, Kanduc D. Pentapeptide sharing between Corynebacterium diphtheria toxin and the human neural protein network. Immunopharmacol Immunotoxicol. 2011;33(2):360-72. https://doi.org/10.31 09/08923973.2010.518618.

88. Amela I, Cedano J, Querol E. Pathogen proteins eliciting antibodies do not share epitopes with host proteins: a bioinformatics approach. PLoS One. 2007;2(6):e512. https://doi.org/10.1371/journal.pone.0000512.

89. Kohm AP, Fuller KG, Miller SD. Mimicking the way to autoimmunity: an evolving theory of sequence and structural homology. Trends Microbiol. 2003;11(3):101-5. https://doi.org/10.1016/50966-842X(03)00006-4.

90. Karlsen AE, Dyrberg T. Molecular mimicry between non-self, modified self and self in autoimmunity. Semin Immunol. 1998;10(1):25-34. https://doi. org/10.1006/smim.1997.0102.

91. Hurford A, Day T. Immune evasion and the evolution of molecular mimicry in parasites. Evolution. 2013;67(10):2889-29904. https://doi.org/10.1111/evo.12171.

92. Lucchese G, Kanduc D. Cytomegalovirus infection: the neurodevelopmental peptide signatures. Curr Drug Discov Technol. 2018;15(3):251-62. https://doi. org/10.2174/1570163814666170829152100.

93. Levison ME, Levison JH. Pharmacokinetics and pharmacodynamics of antibacterial agents. Infect Dis Clin N Am. 2009;23(4):791-815. https://doi. org/10.1016/j.idc.2009.06.008.

94. Shrivastava SR, Shrivastava PS, Ramasamy J. World health organization releases global priority list of antibiotic-resistant bacteria to guide research, discovery, and development of new antibiotics. J Med Soc. 2018;32(1):76-7. https://doi.org/10.4103/jms.jms_25_17.

95. NIAID. Emerging Infectious Diseases/Pathogens. 2018. https://www.niaid.nih. gov/research/emerging-infectious-diseases-pathogens. Accessed 21 Dec 2020.

\section{Publisher's Note}

Springer Nature remains neutral with regard to jurisdictional claims in published maps and institutional affiliations.

\section{Ready to submit your research? Choose BMC and benefit from:}

- fast, convenient online submission

- thorough peer review by experienced researchers in your field

- rapid publication on acceptance

- support for research data, including large and complex data types

- gold Open Access which fosters wider collaboration and increased citations

- maximum visibility for your research: over $100 \mathrm{M}$ website views per year

At BMC, research is always in progress.

Learn more biomedcentral.com/submissions 